\title{
Dose-response relationship between sports activity and musculoskeletal pain in adolescents
}

\section{Citation}

Kamada, Masamitsu, Takafumi Abe, Jun Kitayuguchi, Fumiaki Imamura, I-Min Lee, Masaru Kadowaki, Susumu S. Sawada, Motohiko Miyachi, Yuzuru Matsui, and Yuji Uchio. 2016. "Doseresponse relationship between sports activity and musculoskeletal pain in adolescents." Pain 157 (6): 1339-1345. doi:10.1097/j.pain.0000000000000529. http://dx.doi.org/10.1097/ j.pain.0000000000000529.

\section{Published Version}

doi:10.1097/j.pain.0000000000000529

\section{Permanent link}

http://nrs.harvard.edu/urn-3:HUL.InstRepos:27662319

\section{Terms of Use}

This article was downloaded from Harvard University's DASH repository, and is made available under the terms and conditions applicable to Other Posted Material, as set forth at http:// nrs.harvard.edu/urn-3:HUL.InstRepos:dash.current.terms-of-use\#LAA

\section{Share Your Story}

The Harvard community has made this article openly available.

Please share how this access benefits you. Submit a story.

Accessibility 


\title{
Dose-response relationship between sports activity and musculoskeletal pain in adolescents
}

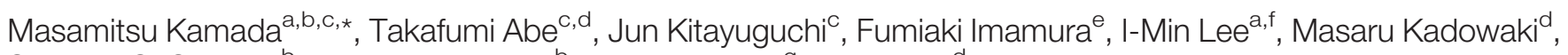
Susumu S. Sawada ${ }^{\mathrm{b}}$, Motohiko Miyachi ${ }^{\mathrm{b}}$, Yuzuru Matsui ${ }^{\mathrm{g}}$, Yuji Uchio ${ }^{\mathrm{d}}$

\begin{abstract}
Physical activity has multiple health benefits but may also increase the risk of developing musculoskeletal pain (MSP). However, the relationship between physical activity and MSP has not been well characterized. This study examined the dose-response relationship between sports activity and MSP among adolescents. Two school-based serial surveys were conducted 1 year apart in adolescents aged 12 to 18 years in Unnan, Japan. Self-administered questionnaires were completed by 2403 students. Associations between time spent in organized sports activity and MSP were analyzed cross-sectionally ( $n=2403$ ) and longitudinally ( $n=374$, students free of pain and in seventh or 10 th grade at baseline) with repeated-measures Poisson regression and restricted cubic splines, with adjustment for potential confounders. The prevalence of overall pain, defined as having pain recently at least several times a week in at least one part of the body, was $27.4 \%$. In the cross-sectional analysis, sports activity was significantly associated with pain prevalence. Each additional $1 \mathrm{~h} /$ wk of sports activity was associated with a $3 \%$ higher probability of having pain (prevalence ratio $=1.03,95 \%$ confidence interval $=$ 1.02-1.04). Similar trends were found across causes (traumatic and nontraumatic pain) and anatomic locations (upper limbs, lower back, and lower limbs). In longitudinal analysis, the risk ratio for developing pain at 1-year follow-up per $1 \mathrm{~h} / \mathrm{wk}$ increase in baseline sports activity was 1.03 (95\% confidence interval $=1.02-1.05)$. Spline models indicated a linear association $(P<0.001)$ but not a nonlinear association $(P \geq 0.45)$. The more the adolescents played sports, the more likely they were to have and develop pain.
\end{abstract}

Keywords: Exercise, Low back pain, Epidemiology, Cumulative trauma disorders, Injuries

\section{Introduction}

Musculoskeletal pain (MSP) is a common health problem among adolescents, with a prevalence ranging from $4 \%$ to $40 \% .^{22}$ In school-aged youth, MSP is associated with not only functional disability ${ }^{15}$ and lower quality of life ${ }^{4}$ but also future risk of MSP during adulthood. ${ }^{17}$ Musculoskeletal pain can be severe enough to require prescription pain medications, which can lead to opioid

Sponsorships or competing interests that may be relevant to content are disclosed at the end of this article.

a Division of Preventive Medicine, Brigham and Women's Hospital, Harvard Medical School, Boston, MA, USA, ${ }^{b}$ Department of Health Promotion and Exercise, National Institute of Health and Nutrition, Shinjuku-ku, Tokyo, Japan, ${ }^{c}$ Physical Education and Medicine Research Center UNNAN, Unnan, Shimane, Japan, 'Department of Orthopaedics, Shimane University School of Medicine, Izumo, Shimane, Japan, ${ }^{e}$ MRC Epidemiology Unit, Institute of Metabolic Science, University of Cambridge School of Clinical Medicine, Cambridge, United Kingdom, ${ }^{f}$ Department of Epidemiology, Harvard School of Public Health, Boston, MA, USA, ' Unnan City Hospital, Unnan, Shimane, Japan

*Corresponding author. Address: Division of Preventive Medicine, Brigham and Women's Hospital, Harvard Medical School, 900 Commonwealth Ave East, Boston, MA 02215, USA. Tel.: +1 617732 8812; fax: +1 617731 3843. E-mail address: kamada@gakushikai.jp (M. Kamada).

Supplemental digital content is available for this article. Direct URL citations appear in the printed text and are provided in the HTML and PDF versions of this article on the journal's Web site (www.painjournalonline.com).

PAIN 157 (2016) 1339-1345

C 2016 International Association for the Study of Pain. This is an open access article distributed under the terms of the Creative Commons Attribution-NonCommercial License 4.0 (CC BY-NC), which permits downloading, sharing, and reproducing the work in any medium, provided it is properly cited. The work cannot be used commercially.

http://dx.doi.org/10.1097/j.pain.0000000000000529 misuse among youth. ${ }^{24}$ Pain medications were used for nonmedical reasons by $4.6 \%$ of U.S. adolescents in $2013 .{ }^{31}$

Physical activity, including organized sports, has multiple health benefits for children and adolescents. ${ }^{32,35}$ However, participation in sports may involve intense physical demands and thus results in a higher risk of MSP. The results of previous studies that investigated the relationship between physical activity and pain have been inconsistent ${ }^{28}$; some reported that physical activity increased the risks of lower back ${ }^{21}$ and lower limb pain,,${ }^{9,10}$ traumatic $^{11}$ and overall MSP, ${ }^{23}$ and widespread pain, ${ }^{20}$ whereas others reported the opposite, suggesting that physical activity reduced the risk of back pain. ${ }^{29,36}$ In addition, whether a nonlinear dose-response relationship exists is uncertain. There may be a U-shaped curve, ie, both too little and too much physical activity may increase the risk of MSP, ${ }^{18}$ or there may be a peak or a plateau in the curve. However, most previous studies only evaluated categories of physical activity (eg, tertiles) or tested for a simple linear trend and did not explicitly explore the dose-response curve. To optimize the safety and benefits of physical activity and organized sports for adolescents, understanding the shape of the dose-response curve is important.

We aimed to examine the dose-response relationship between sports activity and MSP among adolescents. In particular, we aimed to test for linear and nonlinear associations using both cross-sectional and longitudinal study designs.

\section{Methods}

\subsection{Study design}

All junior high schools ( 7 schools, seventh to ninth grades, student age 12-15 years) and high schools ( 3 schools, 1 th-12th grades, 
student age 15-18 years) in Unnan (population 43,520, area $553.4 \mathrm{~km}^{2}$ ), Shimane, Japan, participated in this study. In October 2008, and again in October 2009, identical selfadministered questionnaires were distributed to all the students in the participating schools (2267 and 2212 students in 2008 and 2009 , respectively) and returned through the schools. Responses from students who received special needs education and questionnaires with invalid responses (blank forms) were excluded. In total, 1783 (78.7\%) of the students in 2008 and 1897 (85.8\%) of the students in 2009 answered the questionnaires. An explanation of the students' right to decline to answer any question and general information about the study were provided in a letter to the parents or guardians of the students that was included with the questionnaire. Students signed the questionnaire and returned it in an unlabeled envelope. Individual student's answers were not provided to their teachers or sports coaches. This study was approved by the research ethics committee of the Physical Education and Medicine Research Center UNNAN (H19-7-23-5).

We conducted cross-sectional and longitudinal analyses of the data collected. In the cross-sectional analysis, data from both years (2008 and 2009) were used simultaneously; thus, 3680 records from 2403 students, which included both single and repeated measures, were included. Longitudinal analysis was conducted to estimate the risk of developing MSP. Data from 374 students who had filled out the questionnaires in both years and did not suffer from MSP at the time of first assessment were included in the longitudinal analysis. Only students in seventh or 10th grade at baseline (2008) were included in the longitudinal analysis because students in ninth or 12th grade stopped participating in organized sports between July and March to prepare for examinations and graduation, and thus, the assessment of their exposure-outcome relationship was considered incomplete. The inclusion scheme for the data in the analyses is provided in Supplemental Figure S1 (Supplemental Digital Content 1, available online as Supplemental Digital Content at http://links.Iww.com/PAIN/A247). A cross-sectional analysis that excluded ninth and 12th grade students was also conducted as a sensitivity analysis.

\subsection{Measures}

Information on sex, age, weight, and height (converted into body mass index [BMl], in kilograms per square meter), participation in organized sports (in hours per week), sleep time (hours per day from time in until time out of bed), and screen time (hours per week, total time spent watching TV and gaming on weekdays and weekends) were obtained from the questionnaires. Organized sports activity was defined as sports activities that took place after school programs on weekdays and/or weekends or activities that were organized by sports clubs. All students participated in routine physical education throughout the year; this was not included as time spent playing organized sports. For students who participated in organized sports, the questionnaire also asked about the type of sport played. Only 11 students reported participation in multiple types of sports; these students reported the weekly time spent participating in their main sports activity.

To check the test-retest reliability of the weekly organized sports time, 62 students in eighth grade (34 male and 28 female participants) aged 13 to 14 years were asked to answer the questionnaire twice 7 days apart in February 2009. Data from these students were not included in the longitudinal analysis. The intraclass correlation coefficient had an acceptable value (0.85).

\subsection{Pain}

Musculoskeletal pain was assessed using a questionnaire (see eQuestionnaire, Supplemental Digital Content 2, available online as Supplemental Digital Content at http://links.lww.com/PAIN/ A247). Students were considered to suffer from MSP if pain was present recently at least several times a week in at least one part of the body. Musculoskeletal pain locations included the neck, upper limbs, chest, upper back, lower back, buttocks, and lower limbs. In addition, we differentiated types of pain by cause (traumatic or nontraumatic) based on the students' questionnaire responses. The test-retest reliability was also tested in the aforementioned reliability study and found to be acceptable (Cohen kappa for pain in any location $=0.67$ ). After this reliability test, the same students underwent an agreement test (criterion validity test) comprising a face-to-face interview with health professionals trained by an experienced orthopedist. The Cohen kappa was 0.52 , indicating moderate agreement.

\subsection{Statistical analyses}

In the cross-sectional analysis, the overall prevalence of pain at any location was compared across different levels of sports participation by estimating prevalence ratios (PRs) and their 95\% confidence intervals (Cls) using repeated-measures Poisson regression ${ }^{30}$; generalized estimating equations were used to account for the correlation within individuals. ${ }^{16}$ In the longitudinal analysis, the risk of developing MSP was determined by estimating risk ratios (RRs) and 95\% Cls using Poisson regression. ${ }^{30}$ Time spent in sports activity was evaluated both continuously and categorically. Tertiles within students engaged in organized sports activity were used as cutpoints, and students who did not participate in organized sports $(0 \mathrm{~h} / \mathrm{wk})$ were the reference category. To test linearity, sports activity time was also analyzed as a continuous variable (crude and quadratic, separately). Cross-sectional analysis was also performed for the different causes of MSP (traumatic and nontraumatic) and for its different locations (upper limbs, lower back, and lower limbs). These 3 locations were selected based on their higher MSP prevalence than other locations. In addition, the cross-sectional analysis was conducted after stratification by 10 different sports.

Models were adjusted for sex, age, BMl, sleep length, screen time, and school. Body mass index, sleep length, and screen time were treated as categorical variables and divided into tertiles within each grade. School was included in the model as a fixed effect to adjust for all school (cluster) level confounders regardless of whether they were measured or not. ${ }^{6}$ For the longitudinal analysis, school was included as a determinant of covariance structure because the sample size was too small to estimate parameters for different schools.

Continuous associations between the time spent playing sports and the prevalence or overall risk of pain were estimated without assuming linearity by fitting restricted cubic spline models, ${ }^{8}$ with the knots corresponding to the 25th, 50th, and 75 th percentiles of sports activity time $(13.5,16$, and $20.5 \mathrm{~h} / \mathrm{wk}$ for the prevalence; 13, 16, and 20 for the risk). Sports activity time was winsorized at the 99th percentile (34.5 h/wk for the prevalence; 30 for the risk). The covariates were the same as those evaluated in the Poisson models. The PRs and RRs were presented; average probabilities (prevalence and risk) of having or developing pain were also predicted over the range of time spent playing sports.

We also assessed whether excess sports activity was particularly associated with MSP (overall and location-specific) 
among heavier students because overweight adolescents may experience greater impacts of physical activity on MSP than lean adolescents. ${ }^{33}$ This interaction was tested by modeling the interaction between sports activity and BMI for pain prevalence and by examining the joint categories of BMl and sports activity.

Missing information, ranging from $0.1 \%$ for sex to $5.7 \%$ for $\mathrm{BMI}$, was processed using multiple imputation (n datasets $=10$ ) under the missing at random assumption. 5,34 Each imputation was based on regression models of the analyzed variables. The 10 imputed data sets were analyzed independently and combined for inference, accounting for the variability of imputation. ${ }^{5}$ To calculate the pain prevalence, available cases without missing values on pain outcomes were used.

For the sensitivity analyses, the analyses were repeated for complete cases only (1498 cross-sectional; 281 longitudinal). In addition, cross-sectional analyses were repeated excluding students in the ninth or 12th grade, using (1) 2458 records from 1920 students (students could contribute $>1$ record) and (2) data from a single measurement for each of 1816 students. Analyses (2-sided $\alpha<0.05$ ) were performed using SAS version 9.3 and STATA version 13.1.

\section{Results}

Table 1 presents the baseline participant characteristics before multiple imputation. Female (84.5\%) and junior high school $(87.1 \%)$ students had higher response rates compared with male (79.6\%) or high school (76.3\%) students (both $P<0.001)$. Of the 2403 participants included in the cross-sectional analysis, $51.8 \%$ were females. Students had a mean (SD) age of 14.5 (1.8) years. The mean (SD) time spent in organized sports activity was 16.9
(5.7) h/wk for the 1067 (45.3\%) students who participated in organized sports. The upper $5 \%$ of participants spent $\geq 27.0 \mathrm{~h} / \mathrm{wk}$ (95th percentile) in sports activity.

In total, 634 (27.4\%) students had MSP, and nontraumatic pain was more prevalent (509 cases, 22.3\%) than traumatic pain (129, $5.8 \%)$. Figure 1 illustrates the prevalence of pain by location. The lower limbs were the most commonly affected (360, 15.4\%), followed by the upper limbs (224, 9.5\%) and the lower back (202, $8.5 \%)$. In the longitudinal analysis, 82 (22.7\%) students who were pain-free at baseline experienced pain at the 1-year follow-up. These data, stratified by MSP locations and causes, can be found in Table S1 (Supplemental Digital Content 3, available online as Supplemental Digital Content at http://links.Iww.com/PAIN/A247).

\subsection{Cross-sectional analyses}

Cross-sectional analyses showed that sports activity and pain prevalence had a significant linear association; students who spent the most time engaged in sports activity ( $\geq 18.5 \mathrm{~h} / \mathrm{wk}$ ) experienced a 2-fold greater rate of pain than students who did not participate in organized sports after adjustment for covariables (Table 2). The test for linearity was significant $(P<0.001$ for linear; $P=0.40$ for quadratic); each additional $1 \mathrm{~h} / \mathrm{wk}$ of sports activity was associated with a $3 \%$ higher probability of having pain $(\mathrm{PR}[95 \% \mathrm{Cl}]=1.03$ [1.02-1.04]). Similarly significant linear associations were found in the cause- and location-specific analyses. The spline model also showed a linear association between sports activity and pain prevalence (Fig. 2A). The test for nonlinearity was not significant $(P=0.95)$. In addition, $40 \%$ of students were predicted to have pain when they played sports for 21.8 h/wk (Fig. 3A).

Table 1

Baseline characteristics of study participants in Shimane, Japan, 2008 to 2009.

\begin{tabular}{|c|c|c|c|c|}
\hline & \multicolumn{3}{|c|}{ Cross-sectional analysis $(n=2403)^{\star}$} & \multirow[t]{2}{*}{ Longitudinal analysis $(n=374) \dagger$} \\
\hline & Total $(n=2403)$ & No pain $(n=1676)$ & Pain $(n=634)$ & \\
\hline Sex, female \% & $1244,51.8$ & $895,53.4$ & $297,46.9$ & $207,55.4$ \\
\hline Age, y & $14.5(1.8)$ & $14.7(1.8)$ & $14.3(1.8)$ & $13.8(1.6)$ \\
\hline Body mass index, $\mathrm{kg} / \mathrm{m}^{2}$ & $19.6(2.7)$ & $19.6(2.7)$ & $19.6(2.7)$ & $19.0(2.6)$ \\
\hline Sleep length, h/d & $7.4(1.0)$ & $7.4(1.0)$ & $7.5(1.0)$ & $7.6(0.9)$ \\
\hline Screen time, $h / w k$ & $21.5(12.1)$ & $21.4(12.1)$ & $21.7(12.0)$ & $20.8(10.8)$ \\
\hline Organized sports activity, \% & $1067,45.3$ & $643,39.1$ & $392,63.0$ & $213,58.8$ \\
\hline Mean (SD), h/wk‡ & $16.9(5.7)$ & $16.5(5.3)$ & $17.5(6.3)$ & $16.5(5.0)$ \\
\hline \multicolumn{5}{|l|}{ Sports type } \\
\hline Track and field & 42 & 25 & $15(37.5) \S$ & 7 \\
\hline Soft tennis & 75 & 59 & $15(20.3) \S$ & 19 \\
\hline Table tennis & 32 & 29 & $3(9.4) \S$ & 7 \\
\hline Badminton & 46 & 26 & $17(39.5) \S$ & 9 \\
\hline Kendo & 45 & 25 & $20(44.4) \S$ & 3 \\
\hline Judo & 31 & 16 & $14(46.7) \S$ & 4 \\
\hline Karate & 13 & 9 & $3(25.0) \S$ & 7 \\
\hline Swimming & 1 & 0 & $1(100.0) \S$ & 0 \\
\hline \multicolumn{5}{|l|}{ Team sports, $\mathrm{N}$} \\
\hline Baseball & 165 & 97 & $65(40.1) \S$ & 29 \\
\hline Softball & 102 & 56 & $42(42.9) \S$ & 20 \\
\hline Basketball & 106 & 49 & $53(52.0) \S$ & 14 \\
\hline Soccer & 41 & 24 & $15(38.5) \S$ & 7 \\
\hline Volleyball & 197 & 109 & $82(42.9) \S$ & 41 \\
\hline Other & 2 & 2 & $0(0) \S$ & 0 \\
\hline
\end{tabular}

Values are numbers and percent values for categorical variables and mean (SD) for continuous variables. Sample sizes (denominators) of number counts vary due to missing values.

* Single data (the first response data) for each student.

† Students who had no pain and were in seventh or 10 th grade at baseline.

$\ddagger$ Limited to sports players (1067 [45.3\%] for the cross-sectional analysis; 213 [58.8\%] for the longitudinal analysis).

$\S$ Pain prevalence (\%) within sports type. 


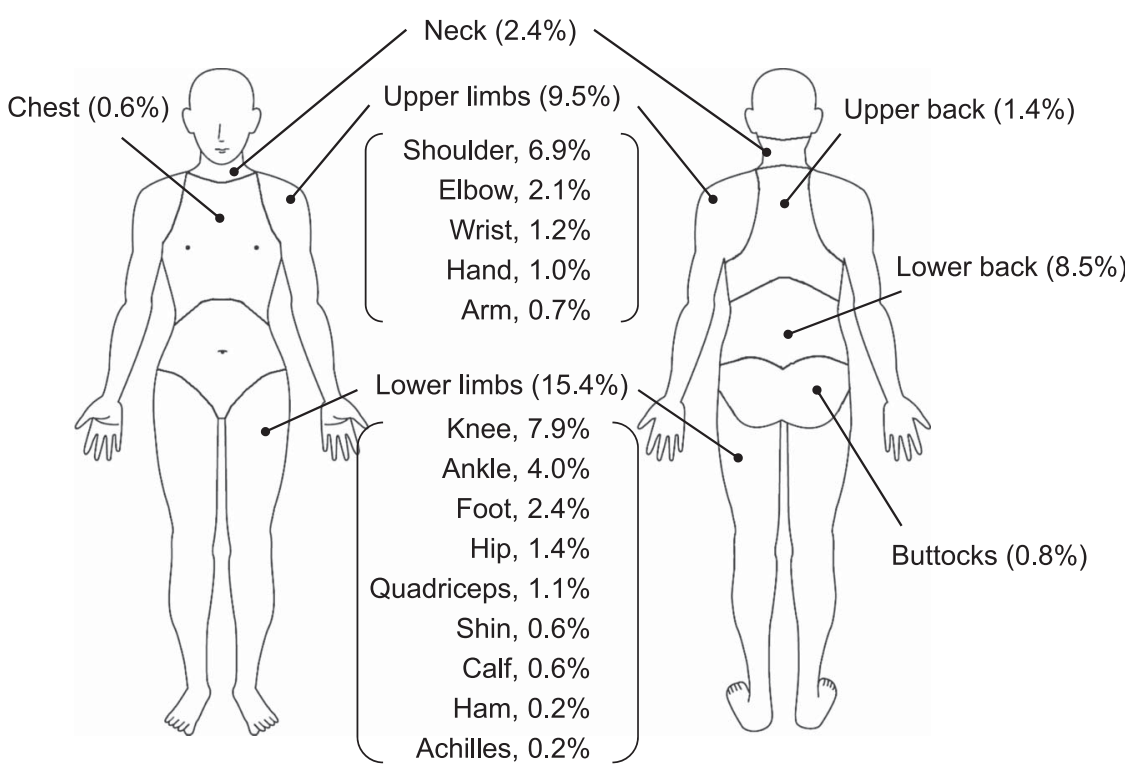

Figure 1. Pain prevalence at various anatomic locations among adolescents $(n=2403)$.

In the cross-sectional analyses stratified by sports type, most sports had a significant linear association between activity time and pain ( $\mathrm{PR}=1.03-1.05$ per $\mathrm{h} / \mathrm{wk}$ ). However, certain sports with small sample sizes, especially soft tennis and table tennis, had lower pain prevalences (20.3\% and $9.4 \%$, respectively; Table 1) and no significant associations between time and pain $(P$ for linearity >0.75; see Table S2, Supplemental Digital Content 4, available online as Supplemental Digital Content at http://links. Iww.com/PAIN/A247).
The interaction between BMl and sports activity was not significantly associated with the overall pain prevalence $(P=$ $0.95)$; however, this interaction was significant for upper limb pain $(P=0.048)$ but not pain at other locations $(P>0.5)$. In the further stratified analysis, the PRs for upper limb pain were higher across the sports activity levels among participants with higher BMls (Figure S2, Supplemental Digital Content 5, available online as Supplemental Digital Content at http://links. Iww.com/PAIN/A247).

\section{Table 2}

Associations of organized sports activity with prevalence and development of musculoskeletal pain: cross-sectional and longitudinal analysis in Japanese adolescents, 2008 to 2009.

\begin{tabular}{|c|c|c|c|c|c|c|}
\hline & \multicolumn{4}{|c|}{ Organized sports activity } & \multirow[t]{2}{*}{ PR or RR per $1 \mathrm{~h} / \mathrm{wk}$} & \multirow[t]{2}{*}{$P$ for linearity } \\
\hline & No sports & First tertile* & Second tertile* & Third tertile* & & \\
\hline \multicolumn{7}{|l|}{ Analysis of prevalence $†$} \\
\hline Activity range, $\mathrm{h} / \mathrm{wk}$ & 0 & $1.0-14.0$ & $14.2-18.3$ & $\geq 18.5$ & & \\
\hline Overall pain, case/n (\%) & 397/2007 (19.8) & $182 / 501(36.3)$ & $163 / 451(36.1)$ & 205/485 (42.3) & & \\
\hline PR $(95 \%$ Cl) & 1 (Ref) & $1.66(1.37-2.02)$ & $1.72(1.41-2.09)$ & $2.17(1.79-2.62)$ & $1.03(1.02-1.04)$ & $<0.001$ \\
\hline \multicolumn{7}{|l|}{ Cause-specific } \\
\hline Traumatic, case/n (\%) & 70/1965 (3.6) & $36 / 485(7.4)$ & 29/438 (6.6) & $36 / 462(7.8)$ & & \\
\hline PR $(95 \%$ Cl) & 1 (Ref) & $1.85(1.18-2.91)$ & $1.73(1.09-2.75)$ & $2.61(1.69-4.04)$ & $1.04(1.02-1.05)$ & $<0.001$ \\
\hline Nontraumatic, case/n (\%) & $331 / 1988(16.7)$ & $148 / 491(30.1)$ & $138 / 445(31.0)$ & $169 / 475(35.6)$ & & \\
\hline PR $(95 \%$ Cl) & 1 (Ref) & $1.62(1.31-2.00)$ & $1.70(1.38-2.10)$ & $2.05(1.67-2.52)$ & $1.03(1.02-1.04)$ & $<0.001$ \\
\hline \multicolumn{7}{|l|}{ Location-specific } \\
\hline Upper limb, case/n (\%) & $137 / 2049(6.7)$ & 46/506 (9.1) & $55 / 460(12.0)$ & $81 / 486(16.7)$ & & \\
\hline $\mathrm{PR}(95 \% \mathrm{Cl})$ & 1 (Ref) & $1.39(0.98-1.98)$ & $1.72(1.22-2.41)$ & $2.50(1.83-3.40)$ & $1.04(1.03-1.05)$ & $<0.001$ \\
\hline Lower back, case/n (\%) & $140 / 2059(6.8)$ & $40 / 510(7.8)$ & $46 / 462(10.0)$ & $83 / 489(17.0)$ & & \\
\hline $\mathrm{PR}(95 \% \mathrm{Cl})$ & 1 (Ref) & $1.29(0.88-1.90)$ & $1.83(1.28-2.64)$ & $2.76(2.01-3.81)$ & $1.04(1.03-1.05)$ & $<0.001$ \\
\hline Lower limb, case/n (\%) & 187/2044 (9.2) & $128 / 506(25.3)$ & 99/456 (21.7) & $124 / 485(25.6)$ & & \\
\hline PR $(95 \%$ Cl) & 1 (Ref) & 2.19 (1.69-2.83) & $1.99(1.53-2.59)$ & $2.86(2.21-3.69)$ & $1.04(1.03-1.05)$ & $<0.001$ \\
\hline \multicolumn{7}{|l|}{ Analysis of riskł } \\
\hline Activity range, h/wk & 0 & $4.0-14.0$ & $14.5-18.0$ & $\geq 18.5$ & & \\
\hline Overall pain, case/n (\%) & $18 / 145$ (12.4) & $27 / 76(35.5)$ & $13 / 65(20.0)$ & $20 / 58(34.5)$ & & \\
\hline $\mathrm{RR}(95 \% \mathrm{Cl})$ & 1 (Ref) & $1.98(1.20-3.26)$ & $1.30(0.78-2.16)$ & $2.61(1.67-4.09)$ & $1.03(1.02-1.05)$ & $<0.001$ \\
\hline
\end{tabular}

Case/ $\mathrm{n}$ is the number of pain cases and the total number of records in each category from the available cases before imputation. Multiple records from an adolescent are possible in the serial cross-sectional analysis. * Tertile categories were created among those reporting any sports activity separately for cross-sectional and for longitudinal analysis.

† Prevalence ratios and 95\% Cls were estimated by Poisson regression adjusted for sex, age, body mass index, sleep length, screen time, and school. 0 f 2403 adolescents, 1277 had repeated measures (total 3680 records). $\ddagger$ Risk ratios and $95 \% \mathrm{Cl}$ were estimated by Poisson regression in which measures collected in 2008 were fitted to estimate risk of developing pain in 2009 in 374 adolescents who reported no musculoskeletal pain in 2008. Covariates included in the model were the same as for the cross-sectional analysis for PR, with the exception that school categories were included in the model as a determinant of covariance.

$\mathrm{Cl}$, confidence interval; PR, prevalence ratio; RR, risk ratio. 
A Cross-sectional analysis

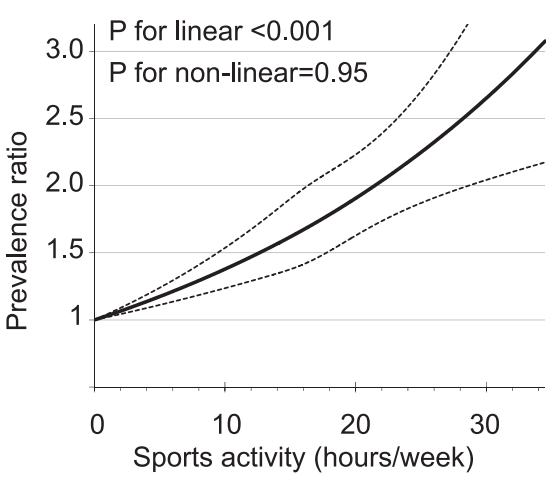

B Longitudinal analysis

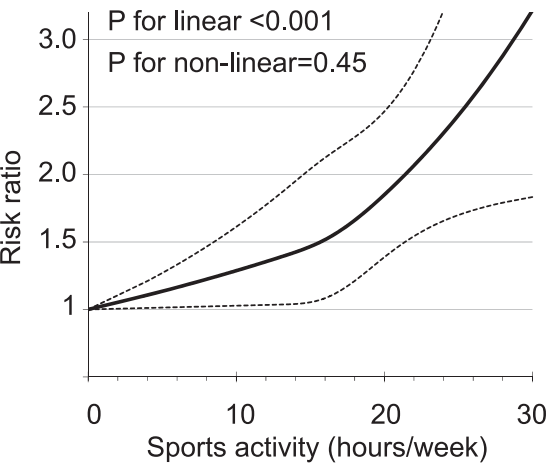

Figure 2. Pain prevalence ratio and risk ratio of having pain at 1 -year follow-up by time spent in sports activity. The solid lines present the adjusted prevalence ratio $(A ; n=2403)$ and risk ratio $(B ; n=374)$ derived from spline regression models. The dashed lines show the $95 \%$ confidence intervals.

\subsection{Longitudinal analyses}

Longitudinal analyses also revealed a linear association between sports activity and new onset of pain. The RR $(95 \% \mathrm{Cl})$ of developing pain at any location at 1 -year follow-up per $1 \mathrm{~h} / \mathrm{wk}$ of sports time at baseline was $1.03(1.02-1.05)(P<0.001$ for linear, $P=0.92$ for quadratic; Table 2). The spline model also showed a linear association between sports activity and 1-year risk of pain (Figs. 2B and 3B). The test for nonlinearity was not significant $(P=0.45)$. The point estimate of the risk ratio reached 2.0 at 21.5 $\mathrm{h} /$ wk of sports activity, indicating the probability of developing pain doubled at that level of exposure.

All these results from multiple imputed analyses were similar to those from complete-case analyses. The variability of 10-time imputation, incorporated in the primary analyses, was $<10 \%$ of total variance. Sensitivity cross-sectional analyses without students in the ninth or 12th grades, made using repeated measurements and single measurements, also yielded similar results. The PRs (95\% Cl) of pain per $1 \mathrm{~h} / \mathrm{wk}$ of sports activity for both the repeated and the single measurement analyses were 1.03 (1.02-1.04).

\section{Discussion}

This study examined the dose-response relationship between organized sports activity and MSP among adolescents and found a linear association. Notably, a series of analyses rejected nonlinearity, and there was no inverse relationship (or protective effect) of sports activity on MSP. The more the participants played sports, the more likely they were to have and develop pain. Our results indicate that if an adolescent increases their sports activity by $1 \mathrm{~h} / \mathrm{wk}$, they have a $3 \%$ higher probability of developing pain 1 year later.

To our knowledge, our longitudinal analysis is the first of its kind to describe the dose-response relationship between sports activity and MSP through detailed analyses, including spline models. We confirmed that there was no $U$-shaped or plateaued trend for the positive association. A previous cross-sectional study of Canadian youth found that the dose-response relationship between physical activity and related injuries outside of school was a strong gradient relationship (linear in grades 6-8; quadratic in grades 9-10). ${ }^{19}$ Other studies have shown similar results from categorical analyses; British children who spent $>360 \mathrm{~min} /$ wk playing sports had a higher risk of widespread pain than those who spent $<100 \mathrm{~min} / \mathrm{wk}$ (cross-sectional relative risk $=1.9$; 1-year longitudinal relative risk $=2.0) .{ }^{20}$ In Finnish schoolchildren, vigorous exercise 5 to 7 times per week increased the risk of new-onset traumatic MSP at 1-year follow-up. ${ }^{11}$ However, some studies reported that physical activity reduced the risk of back pain. ${ }^{29,36}$ These differences may be partly due to methodological differences between the studies. For example, the study showing an inverse association used an accelerometer
A Cross-sectional analysis

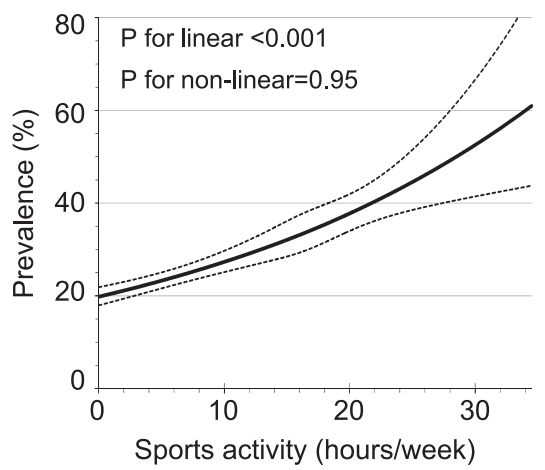

B Longitudinal analysis

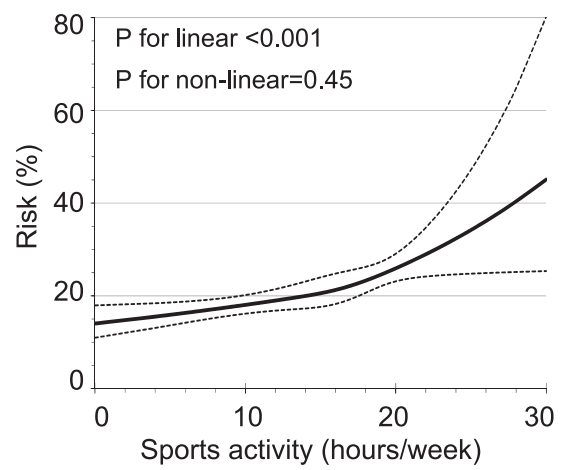

Figure 3. Predicted prevalence and 1-year risk of pain by time spent in sports activity. Multivariable-adjusted models with restricted cubic spline were fitted for prediction of prevalence $(A ; n=2403)$ and risk $(B ; n=374)$. 
to assess overall physical activity in a small sample of 9-year-old children, ${ }^{36}$ whereas most other studies used self-reported measurements in older populations. Our study focused on organized sports activity, and overall physical activity was not measured; thus, our results are not directly comparable with those of studies examining overall physical activity. Legault et al. ${ }^{25}$ suggested that adolescent athletes had fewer symptoms affecting the spine than "typical adolescents" and similar prevalence of symptoms affecting the body's extremities. However, their cross-sectional study had lower response rate (51.1\% and $67.6 \%$ for the athlete adolescents and general adolescents, respectively) than those of other studies including ours, and the representativeness of the adolescent athlete population was questionable. Future meta-analysis of the literature might further clarify the relationship between physical activity and pain in school-aged youth.

We found that sports activity was associated with both traumatic and nontraumatic MSP. Both acute and chronic (overuse) injuries can be caused by excessive sports training, especially in skeletally immature adolescents. ${ }^{2}$ Some of these overuse injuries may have been captured by our questionnaire as nontraumatic pain. More than $80 \%$ of the pain in our study was reported as nontraumatic, which means there was no obvious event that acutely caused the symptoms. Its observed linear association with nontraumatic pain suggests a potential "silent killer" effect of prolonged sports activity.

The interaction between sports activity and BMI was significant for upper but not for lower limb pain, which was contrary to our hypothesis that the combined effect of excess body weight and sports activity might be more harmful to the lower limb joints (because of a higher physical load) than to the joints of the upper limb. ${ }^{33}$ In a previous study, overweight was a risk factor for repeated forearm fractures. ${ }^{13}$ Poor gross motor ability, including balance, in the overweight population ${ }^{14}$ might explain the observed association.

Musculoskeletal pain prevalence $(27.4 \%)$ in our study was within the range of the previous results, ${ }^{22}$ and lower back pain prevalence (9.2\%) was consistent with a previous report in a Japanese population (9.7\%). ${ }^{27}$ The high MSP prevalence, and its linear association with sports activity, suggests the need for preventive actions. To prevent overuse injuries, limiting the weekly and yearly participation time in sports is recommended by the American Medical Society for Sports Medicine. ${ }^{7}$ A systematic review showed that multi-intervention training programs (eg, balance training, structured warm-ups) effectively prevented sports injuries. ${ }^{1}$ These evidence-based prevention programs should be disseminated broadly and evaluated in implementation studies. $^{12}$

The American Academy of Pediatrics has highlighted the potential risks of sports specialization in young athletes. ${ }^{2}$ Most of the students in this study participated in only one sport. The benefits of participation in multiple sports should be examined in future prospective studies. ${ }^{3}$

This study had several strengths. First, MSP was assessed by a questionnaire developed for school-based surveys in adolescents; this tool was confirmed to be reliable and valid in our study. Cause- and location-specific analyses of data obtained from the questionnaire provided in-depth information on the relationship between sports activity and pain. Second, the longitudinal analysis is a strength of this study, although it had a smaller sample size. Finally, this study recruited participants from all schools in the city, including students with elite athletic levels, and thus, our findings are generalizable to a general adolescent population rather than specifically applicable to limited elite athletes or clinically ill patients. Although the participants were recruited from a limited area in Japan, the average weekly time spent in sports activity (16.9 h/wk) was similar to that from a national survey of Japanese junior high school students (average physical activity time, excluding time in physical education class, among those participating in organized sports activity $=16.9 \mathrm{~h} / \mathrm{wk}$ for male participants; 16.4 for female participants). ${ }^{26}$

This study also had several limitations. First, despite the reliability assessment, self-reported sports activity may have been subject to recall bias. Other covariables were also self-reported, with unknown validity. Second, effects of unmeasured factors that may influence sports-MSP relationship, including puberty, smoking, mood of the adolescents, headache, tiredness, and socioeconomic status, could not be accounted for in this study. Third, the outcome of the longitudinal analysis was based on a single measurement at 1-year follow-up. Therefore, the risk of pain developing may have been underestimated because of undetected pain between questionnaire administrations. Finally, we did not examine the differences in the relationship between different durations or severities of pain and sports activity. Further study is needed to explore this.

In conclusion, sports activity had a clear linear association with MSP prevalence and risk among Japanese adolescents. The more the participants played sports, the more likely they were to have and develop pain. Each $1 \mathrm{~h} / \mathrm{wk}$ of additional sports activity time was associated with a $3 \%$ higher probability of having or developing MSP. To optimize the safety and benefits of organized sports activity for adolescents, prevention of MSP should be an important consideration.

\section{Conflict of interest statement}

The authors have no conflicts of interest to declare.

This study was supported by a Grant-in-Aid from the Ministry of Education, Culture, Sports, Science and Technology (MEXT) of Japan. M. Kamada is supported by a JSPS Postdoctoral Fellowship for Research Abroad. F. Imamura is supported by the Medical Research Council Epidemiology Unit (MC_UU_12015/1; MC_UU_12015/5). The funding bodies did not have a role in the study design, intervention, collection, analysis, or interpretation of data; writing the report; or the decision to submit the report for publication.

\section{Acknowledgements}

The authors deeply appreciate the cooperation of the staff members and all other people involved in this study.

\section{Appendix A. Supplemental Digital Content}

Supplemental Digital Content associated with this article can be found online at http://links.Iww.com/PAIN/A247.

\section{Article history:}

Received 5 January 2016

Received in revised form 3 February 2016

Accepted 9 February 2016

Available online 27 February 2016

\section{References}

[1] Aaltonen S, Karjalainen H, Heinonen A, Parkkari J, Kujala UM. Prevention of sports injuries: systematic review of randomized controlled trials. Arch Intern Med 2007;167:1585-92. 
[2] American Academy of Pediatrics. Committee on sports medicine and fitness. Intensive training and sports specialization in young athletes. Pediatrics 2000;106:154-7.

[3] Auvinen JP, Tammelin TH, Taimela SP, Zitting PJ, Mutanen PO, Karppinen الJ. Musculoskeletal pains in relation to different sport and exercise activities in youth. Med Sci Sports Exerc 2008;40:1890-900.

[4] Balague F, Ferrer M, Rajmil L, Pont Acuna A, Pellise F, Cedraschi C. Assessing the association between low back pain, quality of life, and life events as reported by schoolchildren in a population-based study. Eur J Pediatr 2012;171:507-14.

[5] Barnard J, Meng XL. Applications of multiple imputation in medical studies: from AIDS to NHANES. Stat Methods Med Res 1999;8:17-36.

[6] Brumback BA, Dailey AB, Brumback LC, Livingston MD, He Z. Adjusting for confounding by cluster using generalized linear mixed models. Stat Probab Lett 2010;80:1650-4.

[7] DiFiori JP, Benjamin HJ, Brenner JS, Gregory A, Jayanthi N, Landry GL, Luke A. Overuse injuries and burnout in youth sports: a position statement from the American Medical Society for Sports Medicine. Br J Sports Med 2014;48:287-8.

[8] Durrleman S, Simon R. Flexible regression models with cubic splines. Stat Med 1989;8:551-61.

[9] El-Metwally A, Salminen JJ, Auvinen A, Kautiainen H, Mikkelsson M. Lower limb pain in a preadolescent population: prognosis and risk factors for chronicity-a prospective 1- and 4-year follow-up study. Pediatrics 2005;116:673-81.

[10] El-Metwally A, Salminen JJ, Auvinen A, Kautiainen H, Mikkelsson M. Risk factors for traumatic and non-traumatic lower limb pain among preadolescents: a population-based study of Finnish schoolchildren. BMC Musculoskelet Disord 2006;7:3.

[11] El-Metwally A, Salminen JJ, Auvinen A, Macfarlane G, Mikkelsson M. Risk factors for development of non-specific musculoskeletal pain in preteens and early adolescents: a prospective 1-year follow-up study. BMC Musculoskelet Disord 2007;8:46.

[12] Finch CF, Donaldson A. A sports setting matrix for understanding the implementation context for community sport. Br J Sports Med 2010;44: 973-8.

[13] Goulding A, Grant AM, Williams SM. Bone and body composition of children and adolescents with repeated forearm fractures. J Bone Miner Res 2005;20:2090-6.

[14] Graf C, Koch B, Kretschmann-Kandel E, Falkowski G, Christ H, Coburger S, Lehmacher W, Bjarnason-Wehrens B, Platen P, Tokarski W, Predel HG, Dordel S. Correlation between BMI, leisure habits and motor abilities in childhood (CHILT-project). Int $\mathrm{J}$ Obes Relat Metab Disord 2004;28:22-6.

[15] Guite JW, Logan DE, Sherry DD, Rose JB. Adolescent self-perception: associations with chronic musculoskeletal pain and functional disability. J Pain 2007;8:379-86.

[16] Hanley JA, Negassa A, Edwardes MD, Forrester JE. Statistical analysis of correlated data using generalized estimating equations: an orientation. Am J Epidemiol 2003;157:364-75.

[17] Harreby M, Neergaard K, Hesselsoe G, Kjer J. Are radiologic changes in the thoracic and lumbar spine of adolescents risk factors for low back pain in adults? A 25-year prospective cohort study of 640 school children. Spine (Phila Pa 1976) 1995;20:2298-302.

[18] Heneweer H, Vanhees L, Picavet HS. Physical activity and low back pain: a U-shaped relation? PAIN 2009;143:21-5.

[19] Janssen I, Dostaler S, Boyce WF, Pickett W. Influence of multiple risk behaviors on physical activity-related injuries in adolescents. Pediatrics 2007;119:e672-80.
[20] Jones GT, Silman AJ, Macfarlane GJ. Predicting the onset of widespread body pain among children. Arthritis Rheum 2003;48:2615-21.

[21] Jones GT, Watson KD, Silman AJ, Symmons DP, Macfarlane GJ. Predictors of low back pain in British schoolchildren: a population-based prospective cohort study. Pediatrics 2003;111:822-8.

[22] King S, Chambers CT, Huguet A, MacNevin RC, McGrath PJ, Parker L, MacDonald AJ. The epidemiology of chronic pain in children and adolescents revisited: a systematic review. PAIN 2011;152:2729-38.

[23] Kujala UM, Taimela S, Viljanen T. Leisure physical activity and various pain symptoms among adolescents. Br J Sports Med 1999;33:325-8.

[24] Lankenau SE, Teti M, Silva K, Jackson Bloom J, Harocopos A, Treese M. Initiation into prescription opioid misuse amongst young injection drug users. Int J Drug Policy 2012;23:37-44.

[25] Legault É, Descarreaux M, Cantin V. Musculoskeletal symptoms in an adolescent athlete population: a comparative study. BMC Musculoskelet Disord 2015;16:210.

[26] Ministry of Education, Culture, Sports, Science and Technology. National physical fitness and physical activity survey. Japan: Ministry of Education, Culture, Sports, Science and Technology, 2014. Available at: http:// www.mext.go.jp/a_menu/sports/kodomo/zencyo/1353812.htm. Accessed December 22, 2015.

[27] Sato T, Ito T, Hirano T, Morita O, Kikuchi R, Endo N, Tanabe N. Low back pain in childhood and adolescence: assessment of sports activities. Eur Spine J 2011;20:94-9.

[28] Sitthipornvorakul E, Janwantanakul P, Purepong N, Pensri P, van der Beek AJ. The association between physical activity and neck and low back pain: a systematic review. Eur Spine J 2011;20:677-89.

[29] Sjolie AN. Associations between activities and low back pain in adolescents. Scand J Med Sci Sports 2004;14:352-9.

[30] Spiegelman D, Hertzmark E. Easy SAS calculations for risk or prevalence ratios and differences. Am J Epidemiol 2005;162:199-200.

[31] Substance Abuse and Mental Health Services Administration. Results from the 2013 national Survey on drug use and health: summary of national findings. Rockville: Substance Abuse and Mental Health Services Administration, 2014. Available at: http://www.samhsa.gov/data/sites/ default/files/NSDUHresultsPDFWHTML2013/Web/NSDUHresults2013. pdf. Accessed December 22, 2015

[32] U.S. Department of Health and Human Services. Physical activity guidelines for Americans. U.S. Department of Health and Human Services, 2008. Available at: http://health.gov/paguidelines/guidelines/ default.aspx. Accessed December 22, 2015.

[33] Urquhart DM, Soufan C, Teichtahl AJ, Wluka AE, Hanna F, Cicuttini FM. Factors that may mediate the relationship between physical activity and the risk for developing knee osteoarthritis. Arthritis Res Ther 2008;10:203.

[34] Vandenbroucke JP, von Elm E, Altman DG, Gotzsche PC, Mulrow CD, Pocock SJ, Poole C, Schlesselman JJ, Egger M. Strengthening the Reporting of Observational Studies in Epidemiology (STROBE): explanation and elaboration. Ann Intern Med 2007;147:W163-194.

[35] Washington RL, Bernhardt DT, Gomez J, Johnson MD, Martin TJ, Rowland TW, Small E, LeBlanc C, Krein C, Malina R, Young JC, Reed FE, Anderson S, Bolduc S, Bar-Or O, Newland H, Taras HL, Cimino DA, McGrath JW, Murray RD, Yankus WA, Young TL, Fleming M, Glendon M, Harrison-Jones L, Newberry JL, Pattishall E, Vernon M, Wolfe L, Li S; Committee on Sports Medicine and Fitness and Committee on School Health. Organized sports for children and preadolescents. Pediatrics 2001;107:1459-62.

[36] Wedderkopp N, Kjaer P, Hestbaek L, Korsholm L, Leboeuf-Yde C. Highlevel physical activity in childhood seems to protect against low back pain in early adolescence. Spine J 2009;9:134-41. 